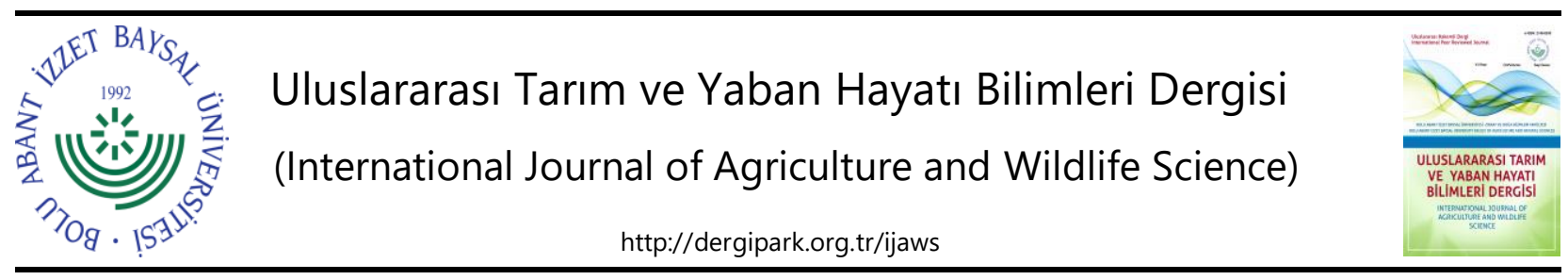

Araştırma Makalesi

\title{
Yerel Beauveria bassiana ve Metarhizium anisopliae İzolatlarının Myzocallis coryli ve Corylobium avellanae Üzerindeki Etkinliği
}

\author{
Salih Karabörklü̈, Nedim Altın \\ Düzce Üniversitesi, Ziraat Fakültesi, Bitki Koruma Bölümü, Düzce \\ Geliş tarihi (Received): 24.07.2020 Kabul tarihi (Accepted): 28.08.2020
}

\begin{abstract}
Anahtar kelimeler:
Findık, Myzocallis coryli,

Corylobium avellanae,

Beauveria bassiana,

Metarhizium anisopliae
\end{abstract}

Özet. Fındık yaprakbiti, Myzocallis coryli ve fındık yeşil afidi, Corylobium avellanae fındıkta zarar oluşturan böcekler arasında yer almaktadır. Bu çalışma, Beauveria bassiana ve Metarhizium anisopliae türü entomopatojen fungusların $M$. coryli ve $C$. avellanae üzerindeki öldürücü etkilerinin belirlenmesi amacıyla yürütülmüştür. Laboratuvar çalışmalarında nimf ve erginlere $1 \times 10^{5}$ konidi ml1 doz püskürtülmüş ve 7 gün boyunca denemeler takip edilmiştir. Uygulama süresi sonunda $B$. bassiana YK26, YK16, YK11 ve M. anisopliae YK45 izolatları sırasıyla M. coryli üzerinde \%81.09, \%73.24, 58.25 ve \%52.45 oranlarında öldürücü etki göstermiştir. EPF izolatlarının C. avellanae üzerinde oldukça etkili oldukları görülmüş ve en etkili izolatlar \%88.9, \%96.75 ve \%98.08 öldürme oranları ile $B$. bassiana YK26, YK11 ve M. anisopliae YK38 olmuştur. Arazi çalışmalarında ise $B$.

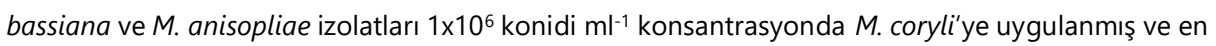
yüksek öldürme oranı \%48.37 ile B. bassiana YK26 izolatında görülmüştür. Bu izolatı \%44.69 ve \%38.49 öldürme oranları ile B. bassiana YK16 ve M. anisopliae YK45 izolatları takip etmiştir. Yaprak bitleriyle mücadelede $B$. bassiana ve M. anisopliae izolatlarının kullanılabileceğine yönelik bulgular elde edilmiştir.
*Sorumlu yazar

salihkaraborklu@duzce.edu.tr

\section{The Effectiveness of the Isolates of Native Beauveria bassiana and Metarhizium anisopliae on Myzocallis coryli and Corylobium avellanae}

Keywords:
Hazelnut, Myzocallis coryli,
Corylobium avellanae,
Beauveriar bassiana,
Metarhizium anisopliae

Metarhizium anisopliae

\begin{abstract}
Filbert aphid, Myzocallis coryli and Hazelnut aphid, Corylobium avellanae are among the harmful insects for the hazelnut production. This study was carried out to determine the lethal effect of entomopathogenic fungi, Beauveria bassiana and Metarhizium anisopliae on M. coryli and C. avellanae. In laboratory application, $1 \times 10^{5}$ conidia $\mathrm{ml}^{-1}$ dose was sprayed to nymphs and adults and trials were evaluated after 7 days. At the end of the application period, B. bassiana YK26, YK16, YK11 and M. anisopliae YK45 isolates caused $81.09 \%, 73.24 \%, 58.25 \%$ and $52.45 \%$ mortality on M. coryli, respectively. EPF isolates were found to be highly effective on $C$. avellanae, and the most effective isolates were B. bassiana YK26, YK11 and M. anisopliae YK38 with $88.90 \%, 96.75 \%$ and $98.08 \%$ mortality rates. In field application, B. bassiana and M. anisopliae isolates were applied to M. coryli at a concentration of $1 \times 10^{6}$ conidia $\mathrm{ml}^{-1}$ and the highest mortality rate was observed in $B$. bassiana YK26 isolate with 48.37\%. This isolate was followed by $B$. bassiana YK16 and M. anisopliae YK45 with $44.69 \%$ and $38.49 \%$ mortality rates, respectively. Results indicated that B. bassiana and M. anisopliae isolates can be used for controlling of these aphids.
\end{abstract}




\section{GíRiş}

Fındık zengin besin içeriğinden dolayı oldukça değerli bir tarım ürünü olup birçok ülkede yetiştiriciliği yapılmaktadır (Aydınlı ve ark., 2018). Her ne kadar birçok ülkede yetiştirilse de ülkemiz, dünya fındık üretiminin \%65-75'ini, toplam ihracatın ise \%70-75'ini tek başına karşılamaktadır (Bozoğlu, 2001; Karabörklü ve Altın, 2018). Ülkemiz üretim alanı ve üretim miktarı açısından dünyada ilk sırada yer almasına karşın fındık veriminde henüz istenilen düzeye ulaşamamıştır (Aydınlı ve ark., 2018). Dekara fındık veriminde, 2014-2018 yılları ortalaması göz önüne alındığında ilk sırayı 235.8 kg ile ABD almaktadır. Ülkemizde ise bu oran aynı üretim yılları esas alındığında ortalama $96.2 \mathrm{~kg}$ olarak gerçekleşmiştir (Anonymous, 2019; Şen ve Karabörklü, 2020).

Fındıkta verim ve kalite kaybına neden olan birçok böcek türü bulunmaktadır. Ülkelere, bölgelere ve yıllara bağlı olarak değişmekle birlikte bazı türlerin fındıkta önemli düzeyde ekonomik zarar oluşturduğu bildirilmiştir (Işık ve ark., 1987; Messing ve AliNiazee, 1989; Gantner, 2001; Tuncer, 2009; Miller ve ark., 2019). Fındık zararlılarının meydana getirdiği verim kayıplarının \%20-50 arasında değişiklik gösterdiği rapor edilmiştir (AliNiazee, 1997). Fındık yaprakbiti olarak bilinen Myzocallis coryli Goeze (Hemiptera: Aphididae) ve fındık yeşil afidi olarak bilinen Corylobium avellanae Schrank (Hemiptera: Aphididae) türlerinin birçok ülkede yayllış gösterdikleri ve fındıkta zarar oluşturdukları birçok araştırmacı tarafından rapor edilmiştir (Messing ve AliNiazee, 1989; Gantner, 2001; Tuncer ve Mennan, 2002; Tuncer, 2009; Walton ve ark., 2009a; Miller ve ark., 2019; Aqaverdi ve Inqilab, 2019; Rovira ve ark., 2019; Şen ve Karabörklü, 2020). Yaprakbitleri yaprak, sürgün ve zuruf gibi bitki dokularından özsu emmek ve fumajin oluşturmak suretiyle bitkide zarar oluşturmaktadır (Tuncer ve Mennan, 2002; Walton ve ark., 2009a). Fındık yaprakbitlerinin popülasyon yoğunluğunun arttığı dönemlerde sürgünlerin gelişemediği ve kuruduğu da bildirilmiştir (Tuncer ve Ecevit, 1997).

Böcek patojeni funguslar (entomopatojen funguslar), zararlı böceklere karşı yürütülen biyolojik mücadele çalışmalarında kullanılan en önemli mikroorganizma gruplarından birisidir. Entomopatojen funguslar (EPF) üretmiş oldukları sporlar vasıtasıyla böceklerin kutikulasına rahatlıkla tutunabilmekte, böcek dokuları ve hemosöle ulaşabilmekte ve böcekleri çok kısa sürelerde öldürebilmektedir. Bu özellik entomopatojen funguslara zararlı böceklerle mücadelede önemli bir avantaj kazandırmaktadır. Entomopatojen funguslar ayrıca trake, yaralanmış vücut bölgeleri, sindirim sistemi ve diğer açıklıklar yoluyla da konukçuya nüfuz edebilmekte ve konukçuyu öldürebilmektedir (Shah ve Pell, 2003; Goettel ve ark., 2005; Sevim ve ark., 2015; Batta ve Kavallieratos, 2018; Karabörklü ve ark., 2018, 2019; Keskin ve ark., 2019). Birçok EPF türüne ait ticari formülasyonlar geliştirilmiş olup birçok zararlı böceğe karşı başarıyla kullanılmaktadır. Beauveria bassiana (Balsamo) Vuillemin ve Metarhizium anisopliae (Metschnikof) Sorokin önemli EPF türleri arasında yer almaktadır (Rath, 2000; Meyling ve ark., 2018; Karabörklü ve ark., 2020).

Bu çalışma, bazı yerel Beauveria bassiana ve Metarhizium anisopliae izolatlarının fındık yaprak bitleri, Myzocallis coryli ve Corylobium avellanae üzerindeki öldürücü etkilerinin belirlenmesi amacıyla gerçekleştirilmiştir.

\section{MATERYAL VE METOT}

\section{Fındık Yaprakbitleri}

Fındık yaprak bitlerine ait nimf ve erginler Düzce'de (Merkez/Arapçiftliği) bulunan bir fındık bahçesinden 2019 yılı haziran ayı içerisinde toplanmıştır (Şen ve Karabörklü, 2020). Zararlıların bulunduğu uç sürgünlerden örneklerden alınarak laboratuvara getirilmiş ve $23 \pm 2^{\circ} \mathrm{C}$ sıcaklığa, $\% 65 \pm 5$ neme ve $14: 10$ saatlik fotoperiyoda ayarlanmış iklim odasında uygulama anına kadar muhafaza edilmiştir. M. coryli ve C. avellanae türlerinin morfolojik özelliklerinden yola çıkılarak tür tanımlamaları yapılmıştır (Tuncer ve Mennan 2002; Blackman ve Eastop, 2006; Walton ve ark., 2009b; Labanowski ve Soika 2011; Anonim, 2017).

\section{EPF İzolatlart}

Bu çalışmada Düzce ilinden izole edilen ve daha önce tanımlanmış olan EPF türlerine ait yerel izolatlar kullanılmıştır (Karabörklü ve ark., 2019). Beauveria bassiana türünden YK11, YK16 ve YK26 ve Metarhizium anisopliae türünden YK38 ve YK45 olmak üzere toplam 5 adet izolat kullanılmıştır. Stok kültürlerden alınan izolatlar Patates Dekstroz Agar (PDA) besi ortamına ekilmiştir. Ekim sonrası izolatlar konidiospor üretimi ve gelişimlerinin takibi amacıyla $10-15$ günlük süreyle $23 \pm 2^{\circ} \mathrm{C}$ sıcaklığa, \%65 \pm 5 neme ve $14: 10$ saatlik fotoperiyoda ayarlanmış iklim odasında tutulmuştur (Karabörklü ve ark., 2020).

\section{Spor Süspansiyonlart}

İzolatların koidiospor gelişimini takiben her bir izolat için spor süspansiyonları hazırlanmıştır. Bu amaçla PDA besi yerinde gelişen konidiosporlar kazıma yöntemi kullanılarak distile su içerisine alınmıştır. Hazırlanan spor 
süspansiyonlarından alınan örnekler mikroskopta bir hemositometre yardımıyla sayılarak bir izolat için spor yoğunluğu $1 \times 10^{5}$ konidi ml$^{-1}$ olacak şekilde ayarlanmıştır. Daha sonra süspansiyonlar $20 \mathrm{ml}^{\prime}$ lik plastik sprey şişelere aktarılmıştır. Daha sonra sporların homojen dağılımını sağlamak amacıyla her bir sprey şişesine \%0.03 oranında Tween 80 eklenmiştir.

\section{Laboratuvar Denemeleri}

İzolatların etkinliklerinin belirlenmesi amacıyla araziden toplanan $M$. coryli ve $C$. avellanae nimf ve erginleri sayılarak 1 It'lik pet kavanozlara alınmıştır. Her bir kavanoza ortalama 25 adet nimf/ergin konulmuş ve beslenmeleri amacıyla fındık uç sürgününe ait üçer adet ortalama büyüklükte yaprak konulmuştur. Her bir izolat için hazırlanan $1 \times 10^{5}$ spor yoğunluğuna (konidi $\mathrm{ml}^{-1}$ ) sahip süspansiyonlar püskürtme yoluyla nimf ve erginlere uygulanmıştır. Kontrol grubuna ise içerisinde yalnızca \%0.03'lük oranda Tween 80 bulunan saf su uygulaması yapılmıştır. Uygulamadan 7 gün sonra sayım yapılarak canlı ve ölü sayıları belirlenmiştir. Uygulama sonunda her bir izolat için \% etki değerleri hesaplanmıştır. Denemeler beş tekrarlı olarak yürütülmüş ve iklim odasında gerçekleştirilmiştir.

\section{Arazi Denemeleri}

Arazi çalışmalarında hedef tür olarak yüksek popülasyon yoğunluğuna sahip olması nedeniyle $M$. coryli seçilmiştir (Şen ve Karabörklü, 2020). EPF izolatı olarak ise M. coryli üzerinde laboratuvar koşullarında yüksek etkinlik gösteren B. bassiana YK16 ve YK26 ve M. anisopliae YK45 izolatları seçilmiştir. Her bir izolat için hazırlanan $1 \times 10^{6}$ konidi $\mathrm{ml}^{-1}$ konsantrasyona sahip süspansiyonlar üzerinde $M$. coryli nimf ve erginlerinin bulunduğu yapraklara püskürtme yoluyla uygulanmıştır. Kontrol grubuna ise içerisinde yalnızca \%0.03'lük oranda Tween 80 bulunan saf su uygulaması yapılmıştır. Seçilen yapraklarda uygulama öncesi ve uygulamanın 3. ve 7. günlerinde canlı sayımı yapılmıştır. Uygulama sonunda her bir izolat ve uygulama süresi için \% etki değerleri hesaplanmıştır. Denemeler 10 tekrarlı olarak yürütülmüştür.

\section{istatistiksel Analiz}

Entomopatojen fungus izolatlarının laboratuvar koşullarındaki \% etkinliklerinin belirlenmesinde Abbott (1925) formülü kullanılmıştır. İzolatların arazi koşullarındaki \% etkinliklerinin belirlenmesinde ise Henderson ve Tilton (1955) tarafından geliştirilen formül kullanılmıştır. İzolatların etkinliklerinin karşılaştırılmasında SPSS programı (SPSS 17.0 commercial software, SPSS, Inc., Chicago, IL) kullanılarak varyans analizi (tek-faktör ANOVA) yapılmışır. Ortalamaların karşılaştırılmasında \%95'lik güven aralığında Tukey-Kramer HSD post-testi kullanılmıştır.

\section{BULGULAR}

\section{Laboratuvar Denemeleri}

Beauveria bassiana ve M. anisopliae izolatlarının M. coryli nimf ve erginleri üzerindeki etkinlikleri $1 \times 10^{5}$ konidi $\mathrm{ml}^{-1}$ konsantrasyon ve 7 günlük uygulama süresi için hesaplanmıştır (Şekil 1). Kontrol grubuyla karşılaştıııldığında bütün izolatlar $M$. coryli üzerinde önemli oranda öldürücü etki göstermiştir ( $F=11.638 ; d f=5 ; P<0.0001)$. En yüksek öldürme oranına \%81.09 ile B. bassiana YK26 izolatı ulaşmıştır. Bu izolatı \%73.24 öldürme oranı ile B. bassiana YK16 izolatı takip etmiştir. En düşük öldürme oranı ise \%34.56 ile M. anisopliae YK38 izolatında tespit edilmiştir (Şekil 1).

Entomopatojen fungus izolatları benzer şekilde püskürtme yoluyla $C$. avellanae nimf ve erginlerine de uygulanmış ve her bir izolatın öldürme oranları hesaplanmıştır (Şekil 2). Bütün izolatların kontrole göre önemli oranda öldürücü etki gösterdiği belirlenmiştir $(F=22.523 ; d f=5 ; P<0.0001)$. En etkili izolatlar $\% 96.75$ ve \%98.08 öldürme oranları ile B. bassiana YK11 ve M. anisopliae YK38 izolatları olmuştur. Bu izolatları \%88.79 öldürme oranı ile B. bassiana YK26 izolatı takip etmiştir. En düşük öldürme oranına sahip izolat ise \%75.81 ile B. bassiana YK16 izolatı olmuştur (Şekil 2). 

Etkinliği

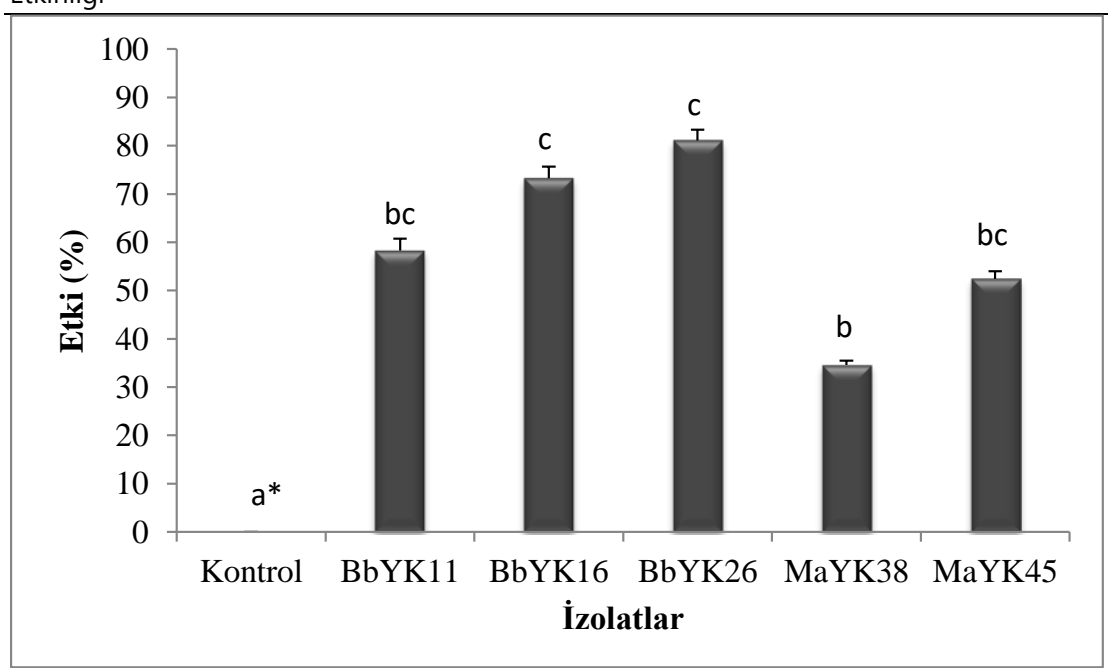

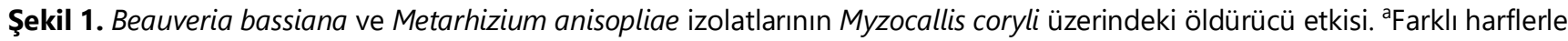
gösterilen ortalamalar arasında önemli farklılık bulunmaktadır $(P<0.05)$. Bb: Beauveria bassiana, Ma: Metarhizium anisopliae. Hata çubukları standart hatayı göstermektedir.

Figure 1. Insecticidal activity of Beauveria bassiana and Metarhizium anisopliae isolates on Myzocallis coryli. There is a significant difference between the means indicated by different letters $(P<0.05)$. Bb: Beauveria bassiana, Ma: Metarhizium anisopliae. Error bars indicate standard error.

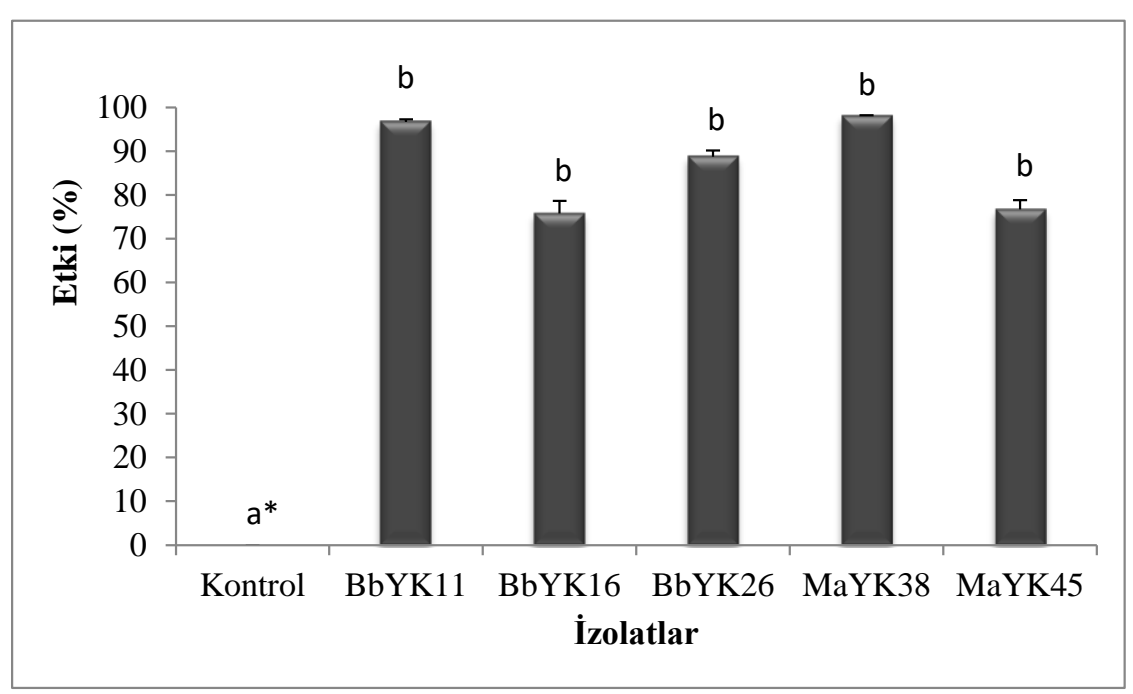

Şekil 2. Beauveria bassiana ve Metarhizium anisopliae izolatlarının Corylobium avellanae üzerindeki öldürücü etkisi. ${ }^{a} F a r k l ı$ harflerle gösterilen ortalamalar arasında önemli farklılık bulunmaktadır $(P<0.05)$. Bb: Beauveria bassiana, Ma: Metarhizium anisopliae. Hata çubukları standart hatayı göstermektedir.

Figure 1. Insecticidal activity of Beauveria bassiana and Metarhizium anisopliae isolates on Corylobium avellanae. There is a significant difference between the means indicated by different letters $(P<0.05)$. Bb: Beauveria bassiana, Ma: Metarhizium anisopliae. Error bars indicate standard error.

\section{Arazi Denemeleri}

Entomopatojen fungus izolatlarının arazi koşullarındaki etkinliklerinin belirlenmesi amacıyla $B$. bassiana türüne ait YK16 ve YK26 izolatları ve $M$. anisopliae türüne ait YK45 izolatı seçilmiş ve $M$. coryli türünün nimf ve erginlerine $1 \times 10^{6}$ konidi ml$^{-1}$ dozda püskürtme yoluyla uygulanmıştır. Uygulama öncesi ve uygulamanın 3. ve 7. günlerine ait sayım sonuçları çizelgede verilmiştir (Çizelge 1.)

Çizelge 1. Uygulama öncesi ve sonrası Myzocallis coryli nimf/ergin sayılarındaki değişim. Table 1. The numbers of Myzocallis coryli nymph/adults for before and after application.

\begin{tabular}{llll}
\hline \multirow{2}{*}{ İolatlar } & \multicolumn{3}{c}{ Ergin/Nimf Sayısı } \\
\cline { 2 - 4 } & Uygulama Öncesi & 3. Gün & 7. Gün \\
\hline Kontrol & $31.20 \pm 5.13$ & $35.13 \pm 6.27$ & $63.14 \pm 8.82$ \\
BbYK23 & $31.60 \pm 4.31$ & $20.90 \pm 4.20$ & $35.38 \pm 9.33$ \\
BbYK26 & $39.40 \pm 5.63$ & $28.50 \pm 5.34$ & $41.17 \pm 9.42$ \\
MaYK45 & $33.00 \pm 5.73$ & $32.80 \pm 8.35$ & $40.83 \pm 8.72$ \\
\hline
\end{tabular}

Bb: Beauveria bassiana, Ma: Metarhizium anisopliae, \pm : Standart hata. 
Entomopatojen fungus izolatlarının arazi koşullarındaki etkinlikleri incelendiğinde uygulamanın 3. gününde en etkili izolatın \%41.25 ile B. bassiana YK16 izolatı olduğu görülmüştür (Şekil 3). Bu izolatı \%35.75 ile B. bassiana YK26 izolatı takip etmiştir. Uygulamanın 7. gününde ise en etkili izolat \%48.37 ile B. bassiana YK26 olmuştur. Bu izolatı ise \%44.69 ve \%38.49 öldürme oranları ile B. bassiana YK16 ve M. anisopliae YK45 izolatları takip etmiştir (Şekil 3).

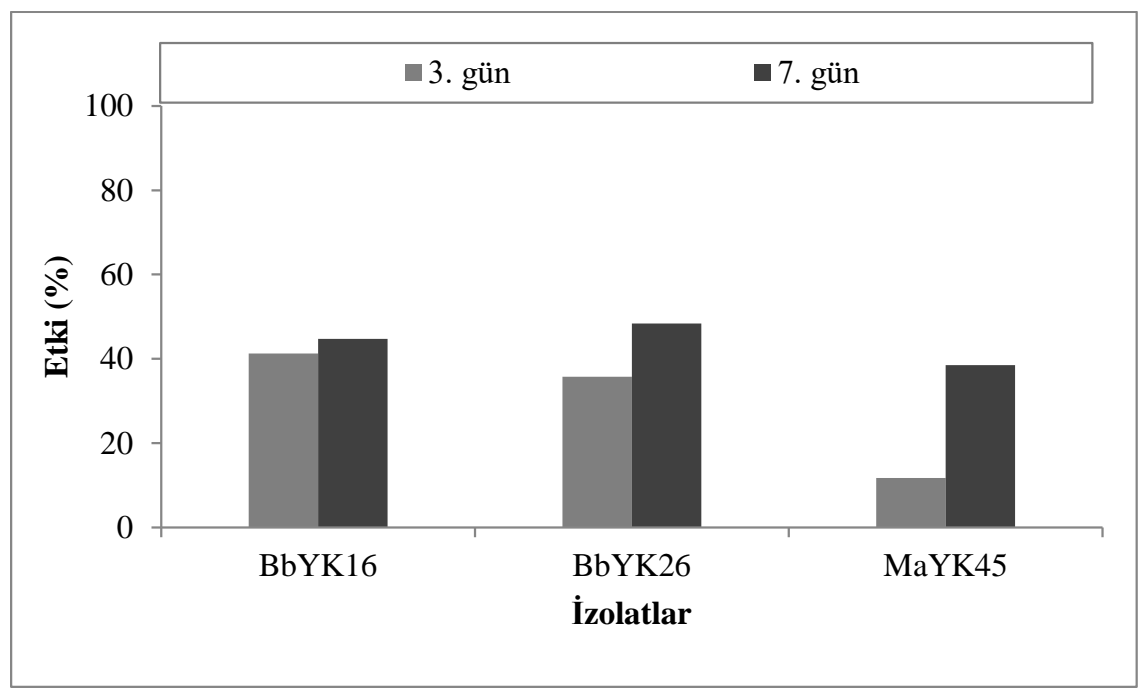

Şekil 3. Arazi uygulaması sonrası entomopatojen fungusların Myzocallis coryli üzerindeki öldürücü etkisi. Bb: Beauveria bassiana, Ma: Metarhizium anisopliae.

Fıgure 3. Insecticidal activity of entomopathogen fungi on Myzocallis coryli after field application. Bb: Beauveria bassiana, Ma: Metarhizium anisopliae.

\section{TARTIŞMA}

Fındık yaprakbiti, Myzocallis coryli ve fındık yeşil afidi, Corylobium avellanae birçok ülkede yayılış göstermekte ve fındıkta zarar oluşturmaktadır. Bu iki türün ülkemizde de oldukça yaygın olduğu ve fındık yetiştirilen bütün alanlarda bulundukları rapor edilmiştir (Lodos, 1986; Tuncer ve Mennan, 2002, Şen ve Karabörklü, 2020). Beauveria bassiana ve M. anisopliae türü entomopatojen funguslardan geliştirilen biyolojik preparatlar küresel ölçekte birçok tarımsal zararlıya karşı başarıyla kullanılmaktadır (Yasin ve ark., 2019). Beauveria bassiana ve M. anisopliae türü fungusların yaprak bitlerine karşı etkili olduğu ve bu zararlılara karşı başarıyla kullanıldığı rapor edilmiştir (Mweke ve ark., 2019; Cheong ve ark., 2020; Singh ve Kaur, 2020). Yapılan çalışmalar incelendiğinde B. bassiana ve $M$. anisopliae türü fungusların diğer yaprak bitleri üzerindeki etkinliklerine yönelik birçok çalışma yürütülmüşken fındık yaprak bitleri, M. coryli ve C. avellanae üzerindeki etkinliklerine yönelik çok sınırlı sayıda çalışma yürütülmüştür (Aker ve Abacl, 2016; Aker ve Tuncer, 2016).

Yaptığımız çalışmada Düzce ilinden elde edilmiş olan yerel B. bassiana ve M. anisopliae izolatlarının fındık yaprak bitleri üzerinde önemli oranda öldürücü etkiye sahip oldukları görülmüştür. Laboratuvar çalışmalarında

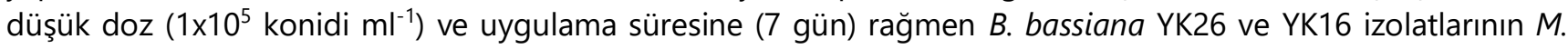
coryli nimf ve erginleri üzerinde sırasıyla \%81.09 ve \%73.24 oranlarında öldürücü etki göstermiştir. Metarhizium anisopliae YK45 izolatı ise \%52.45 oranında öldürücü etki göstermiştir. Beauveria bassiana (SD15) ve M. anisopliae (SD3) izolatlarının şeftali yaprak biti, Myzus persicae (Sulzer) (Hemiptera: Aphididae) üzerinde yüksek etki gösterdikleri belirlenmiştir (Yun ve ark., 2017). Fungal izolatlar B. bassiana (SD15) ve M. anisopliae (SD3) $1 \times 10^{8}$ konidi $\mathrm{ml}^{-1}$ dozda 7 gün süreyle Myzus persicae türüne uygulandığında izolatların sırasıyla \%81.6 ve \%100 oranlarında öldürücü etki gösterdiği rapor edilmiştir (Yun ve ark., 2017). Benzer şekilde B. bassiana (Y-132) ve $M$. anisopliae (Qin-13) izolatları aynı doz ve aynı uygulama süresinin sonunda Myzus persicae üzerinde yaklaşık \%80 oranında öldürücü etki göstermiştir (Rehman ve ark., 2019). Bununla birlikte B. bassiana izolatları (BB-72 ve BB252) aynı yaprak bitine karşı $1 \times 10^{8}$ konidi ml $^{-1}$ dozda 10 gün süreyle uygulandığında sırasıyla \%93 ve 86 oranlarında öldürücü etki göstermiştir (Nazir ve ark., 2019). İzolatlardan B. bassiana BB-72, 1x107 konidi ml ${ }^{-1}$ dozda 10 gün süreyle uygulandığında ise \%92 oranında öldürücü etki göstermiştir (Javed ve ark., 2019).

Fındık yaprak biti üzerindeki çalışmalar incelendiğinde M. anisopliae, Lecanicillium muscarium ve Isaria fumosorosea türü EPF izolatlarının M. coryli'nin 3. dönem nimfleri üzerindeki etkinliklerinin araştıııldığı bir çalışmada en etkili türün M. anisopliae olduğu belirlenmiştir. İzolatlar $1 \times 10^{8} \mathrm{konidi} \mathrm{ml}^{-1}$ olarak uygulandığında 6 . günde sırasıyla \%82.00, \%49.02 ve \%40.60 oranlarında öldürücü etki göstermiştir. En etkili sıcaklık ise $25^{\circ} \mathrm{C}$ olarak 
belirlenmiştir. Uygulamanın 10. gününde ise bu oran M. anisopliae için \%100'e ulaşmıştır (Aker ve Abacl, 2016). Benzer şekilde aynı entomopatojen funguslar ilk dönem M. coryli nimflerine aynı dozda 5 gün süreyle uygulandığında en etkili türün M. anisopliae olduğu ve nimflerin tamamının (\%100) öldüğü görülmüştür (Aker ve Tuncer, 2016).

Entomopatojen fungus izolatlarının C. avellanae üzerinde ise çok daha etkili oldukları tespit edilmiştir. En yüksek öldürücü etki \%96.75, \%98.08 ve \%88.90 öldürme oranları ile B. bassiana YK11, M. anisopliae YK38 ve $B$. bassiana YK26 izolatlarında görülmüştür. Yapılan literatür taramaları sonunda bildiğimiz kadarıyla EPF türlerinin C. avellanae üzerindeki etkinliğine yönelik bir çalışmaya bulunmamaktadır.

Arazi çalışmalarında ise $B$. bassiana ve M. anisopliae izolatları $1 \times 10^{6} \mathrm{konidi} \mathrm{ml}^{-1}$ konsantrasyonda arazide daha yüksek popülasyon yoğunluğuna sahip $M$. coryli türüne uygulandığında nispeten daha düşük öldürücü etki görülmüştür. En yüksek öldürücü etki \%48.37 ile B. bassiana YK26 izolatında görülmüştür. Bu izolatı ise \%44.69 ve \%38.49 öldürme oranları ile B. bassiana YK16 ve M. anisopliae YK45 izolatları takip etmiştir.

\section{SONUÇ}

Sonuç olarak, B. bassiana ve M. anisopliae izolatları laboratuvar koşullarında düşük dozda uygulanmasına karşın fındık yaprakbitleri $M$. coryli ve $C$. avellanae üzerinde önemli oranda öldürücü etki göstermiştir. Arazideki etkinlikleri ise orta düzeyde seyretmiştir. Entomopatojen fungus türlerinin fındık yaprak biti, Myzocallis coryli üzerindeki etkinliğine yönelik çok az çalışma mevcuttur. Fındık yeşil afidi, Corylobium avellanae için ise herhangi bir çalışma-yapılmamıştır. Yaprak bitleriyle mücadelede B. bassiana ve M. anisopliae türlerinin kullanılabileceği belirlenmiştir. Uygulanan dozların yükseltilmesi daha iyi sonuçların alınmasını sağlayacaktır. Ayrıca ilerleyen dönemlerde EPF türlerinin bu zararlılar üzerindeki etkinliklerinin artırılmasına yönelik daha kapsamlı çalışmaların yapılmasına intiyaç duyulacaktır.

\section{ÇIKAR ÇATIŞMASI}

Yazarlar arasında herhangi bir çıkar çatışması bulunmamaktadır.

\section{YAZAR KATKISI}

Yazarlar makalenin bütün aşamalarında eşit düzeyde katkı sağlamışlardır.

\section{TEŞEKKÜR}

Katkılarından dolayı lisans öğrencileri Murat Pişkin ve Selman Adıyaman'a teşekkür ederiz.

\section{KAYNAKLAR}

Aker, O., \& Abacl, S. H. (2016). Entomopathogenicity of Metarhizium anisopliae and some fungi toward the filbert aphid, Myzocallis coryli Goetze (Hemiptera: Aphididae). International Journal of Fauna and Biological Studies, 3(5), 32-37.

Aker, O., \& Tuncer, C. (2016). Efficacy of some entomopathogenic fungi in controlling filbert aphid, Myzocallis coryli Goetze (Hemiptera: Aphididae). International Journal of Entomology Research, 1, 49-53.

AliNiazee, M. T. (1997). Integrated pest management of hazelnut pests: a worldwide perspective. Acta Horticulturae, 445, 469476.

Anonim, (2017). Fındık Entegre Mücadele Teknik Talimatı 2017. Türkiye: T.C. Tarım ve Orman Bakanlığı Tarımsal Araştırmalar ve Politikalar Genel Müdürlüğü, Ankara.

Anonymous, (2019). http://www.fao.org/faostat/en/\#data/QC/. Erişim: 11 Mart 2020.

Aqaverdi, N. I., \& Inqilab, N. G. (2019). Some bioecological peculiarities and predatories of Myzocallis coryli (Goeze, 1778) and Corylobium avellanae (Schrank, 1801) (Hemiptera, Aphididae) in Azerbaijan. American Journal of Entomology, 3(1), 1-5.

Aydınlı, H. Y., Karabörklü, S., \& Aydınlı, V. (2018). Düzce ili fındık bahçelerindeki mayıs böceği (Melolontha melolontha L. Coleoptera, Scarabaeidae) popülasyon yoğunluğu ve yayılışının araştııılması. Selçuk Tarım ve Gıda Bilimleri Dergisi, 32(3), 333-338.

Batta, Y. A., \& Kavallieratos, N. G. (2018). The use of entomopathogenic fungi for the control of stored-grain insects. International Journal of Pest Management, 64(1), 77-87. 
Karabörklü ve Altın, Yerel Beauveria bassiana ve Metarhizium anisopliae İzolatlarının Myzocallis coryli ve Corylobium avellanae Üzerindeki Etkinliği

Blackman, R. L., \& Eastop, V. F. (2006). Aphids on the world's herbaceous plants and shrubs, 1 volume set. John Wiley \& Sons, Chichester, UK.

Bozoğlu, M. (2001). Econometric analysis of hazelnut productivity in Ordu and Giresun provinces, Turkey. Proc. V. Int. Congress on Hazelnut. Ed. S.A. Meh-lenbacher. Acta Horticulturae ISHS 55, 125-129.

Cheong, P. C., Glare, T. R., Rostás, M., Haines, S., Brookes, J. J., \& Ford, S. (2020). Lack of involvement of chitinase in direct toxicity of Beauveria bassiana cultures to the aphid Myzus persicae. Journal of Invertebrate Pathology, 169, 107276.

Gantner M. (2001). Occurance of hazelnut Pests in Southern Poland. Acta Horticulturae, 556, 469-477.

Goettel, M. S., Eilenberg, J., \& Glare, T. (2005). Entomopathogenic fungi and their role in regulation of insect populations. (Ed: L.I. Gilbert, K. latrou, S.S. Gill), Comprehensive Molecular Insect Science, Elseiver, Amsterdam.

Henderson, C. F., \& Tilton E. W. (1955). Test with acaricides against the brow wheat mite. Journal of Economic Entomology, 48, 157-161.

Işık, M., Ecevit, O., Kurt, M. A., \& Yücetin, T. (1987). Doğu Karadeniz Bölgesi Fındık Bahçelerinde Entegre Savaş Olanakları Üzerinde Araştırmalar. Ondokuz Mayıs Üniversitesi Yayınları. Samsun, Türkiye.

Javed, K., Javed, H., Mukhtar, T., \& Qiu, D. (2019). Pathogenicity of some entomopathogenic fungal strains to green peach aphid, Myzus persicae Sulzer (Homoptera: Aphididae). Egyptian Journal of Biological Pest Control, 29(1), 1-7.

Karabörklü, S., \& Altın, N. (2018). Düzce ili fındık depolarında görülen zararlı böcekler ve patojen fungusların tanımlanması. Düzce Bilim ve Teknoloji Dergisi, 6(2), 860-870.

Karabörklü S., Azizoglu, U., \& Azizoglu, Z. B. (2018). Recombinant entomopathogenic agents: a review of biotechnological approaches to pest insect control. World Journal of Microbiology and Biotechnology, 34(1), 14.

Karabörklü S., Altın, N., \& Keskin, Y. (2019). Native Entomopathogenic fungi ısolated from Duzce, Turkey and their virulence on the mealworm beetle Tenebrio molitor L. (Coleoptera: Tenebrionidae). Philippines Agricultural Scientist, 102(1), 82-89.

Karabörklü S., Altın, N., Yıldırım, İ., Öztemis, S., Sadıç, E., \& Aydın, Ö. (2020). Bazı yerel entomopatojen fungusların Amerikan beyaz kelebeğine Hyphantria cunea (Drury) (Lepidoptera: Arctiidae) karşı laboratuvar koşullarındaki insektisidal aktivitesi. Türkiye Biyolojik Mücadele Dergisi, 11(1), 119-128.

Keskin Y., Karabörklü S., \& Altın, N., (2019). Bazı yerel entomopatojen fungusların toprak koşullarındaki etkinliklerinin Tenebrio molitor L. (Col.: Tenebrionidae) larvaları kullanılarak araştırılması. Türkiye Teknoloji ve Uygulamalı Bilimler Dergisi, 2(1), 2631.

Labanowski, G., \& Soika, G., (2011) Aphids (Hemiptera, Aphidoidea) on trees and shrubs belonging to Betulaceae family in ornamental plants nurseries. Aphids and Other Hemipterous Insects, 17, 81-97.

Lodos, N., (1986). Türkiye Entomolojisi II, Genel, Uygulamalı ve Faunistik. Ege Üniversitesi Ziraat Fakültesi Yayınları, Yayın No: 429, İzmir.

Messing, R. H., \& AliNiazee, M.T., (1989). Introduction and establishment of Trioxys pallidus [Hym.: Aphidiidae] in Oregon, U.S.A. for control of filbert aphid Myzocallis coryli [Hom.: Aphididae]. Entomophaga, 34, 153-163.

Meyling, N. V., Arthur, S., Pedersen, K. E., Dhakal, S., Cedergreen, N., \& Fredensborg, B. L. (2018). Implications of sequence and timing of exposure for synergy between the pyrethroid insecticide alpha-cypermethrin and the entomopathogenic fungus Beauveria bassiana. Pest Management Science, 74, 2488-2495.

Miller, B., Dalton, D.T., Xue, L., Stacconi, M.R., \& Walton, V.M. (2019). Use of filbertworm (Cydia latiferreana) mating disruption within a hazelnut IPM program. Crop Protection, 122, 118-124.

Mweke, A., Akutse, K.S., Ulrichs, C., Fiaboe, K.K.M., Maniania, N.K., \& Ekesi, S. (2019). Efficacy of aqueous and oil formulations of a specific Metarhizium anisopliae isolate against Aphis craccivora Koch, 1854 (Hemiptera: Aphididae) under field conditions. Journal of Applied Entomology, 143(10), 1182-1192.

Nazir, T., Basit, A., Hanan, A., Majeed, M.Z., \& Qiu, D. (2019). In vitro Pathogenicity of some entomopathogenic fungal strains against green peach aphid Myzus persicae (Homoptera: Aphididae). Agronomy, 9(1), 7.

Rath, A.C. (2000). The use of entomopathogenic fungi for control of termites. Biocontrol Science and Technology, 10, 563-581.

Rehman, Saif Ur, Ahmed, J.Z.N., Feng, J. N., \& Wang, D. (2019). Potential of four entomopathogenic fungi isolates as biological control agents against two aphid species under laboratory conditions. Pakistan Journal of Agriculural Science, 56(2), 421 429.

Rovira, M., Romero, A., \& Batlle, I. (2019). Hazelnut production and prospects in Spain. Uluslararası Anadolu Ziraat Mühendisliği Bilimleri Dergisi, 1, 86-95. 
Karabörklü ve Altın, Yerel Beauveria bassiana ve Metarhizium anisopliae İzolatlarının Myzocallis coryli ve Corylobium avellanae Üzerindeki Etkinliği

Sevim, A., Sevim, E., \& Demirbağ, Z. (2015). Entomopatojenik fungusların genel biyolojileri ve Türkiye'de zararlı böceklerin mücadelesinde kullanılma potansiyelleri. Erzincan Üniversitesi Fen Bilimleri Enstitüsü Dergisi, 8(1), 115-147.

Shah, P. A., \& Pell, J. K. (2003). Entomopathogenic fungi as biological control agents. Applied Microbiology and Biotechnology, 61, 413-423.

Singh, H., \& Kaur, T. (2020). Pathogenicity of entomopathogenic fungi against the aphid and the whitefly species on crops grown under greenhouse conditions in India. Egyptian Journal of Biological Pest Control, 30(1), 1-9.

Şen, A. Karabörklü S. (2020). Fındık (Corylus avellana) yaprakbitlerinin Düzce'deki mevcut durumunun belirlenmesi. Ziraat Mühendisliği, 370, 54-69.

Tuncer, C., \& Mennan, S. (2002). Fındık yaprak bitleri, Corylobium avellanae Shrank ve Myzocallis coryli Goeze (Homoptera:Aphididae)'nin tanımı üzerinde çalışmalar. Ondokuz Mayıs Üniversitesi Ziraat Fakültesi Dergisi, 17(3), 11-16.

Tuncer, C. (2009). Arthropod pest management in organic hazelnut growing. Acta Horticulturae, 845, 571-578.

Tuncer, C., \& Ecevit, O. (1997). Curent status of hazelnut pests in Turkey. Acta Horticulture, 445, 545-552.

Walton, V. M., Chambers U., \& Olsen, J. L. (2009b). Hazelnut pest and beneficial insects: An identification guide. Corvallis, Or.: Extension Service, Oregon State University.

Walton. V. M., Chambers U., \& Olsen, J. L. (2009a). The current status of the newly invasive hazelnut aphid in Oregon hazelnut orchards. Acta Horticultura. 845, 479-485.

Yasin, M., Wakil, W., Ghazanfar, M. U., Qayyum, M. A., Tahir, M., \& Bedford, G. O. (2019). Virulence of entomopathogenic fungi Beauveria bassiana and Metarhizium anisopliae against red palm weevil, Rhynchophorus ferrugineus (Olivier). Entomological Research, 49, 3-12.

Yun, H. G., Kim, D. J., Gwak, W. S., Shin, T. Y., \& Woo, S. D. (2017). Entomopathogenic fungi as dual control agents against both the pest Myzus persicae and phytopathogen Botrytis cinerea. Mycobiology,45(3), 192-198. 